\title{
Improving Oral-Systemic Healthcare through the Interoperability of Electronic Medical and Dental Records: An Exploratory Study
}

\author{
Lisa Simon ${ }^{1}$ Enihomo Obadan-Udoh ${ }^{2}$ Alfa-lbrahim Yansane ${ }^{3}$ Arti Gharpure ${ }^{3}$ Steven Licht ${ }^{4}$ \\ Jean Calvo ${ }^{5}$ James Deschner $^{6}$ Anna Damanaki $^{7}$ Berit Hackenberg $^{8}$ Muhammad Walji $^{9}$ \\ Heiko Spallek ${ }^{10}$ Elsbeth Kalenderian ${ }^{3}$
}

1 Department of Oral Health Policy and Epidemiology, Harvard School of Dental Medicine, Boston, Massachusetts, United States

2 Department of Preventive and Restorative Dental Sciences, Division of Oral Epidemiology and Dental Public Health, UCSF School of Dentistry, San Francisco, California, United States

${ }^{3}$ Department of Preventive and Restorative Dental Sciences, UCSF School of Dentistry, San Francisco, California, United States

${ }^{4}$ University of Pittsburgh School of Dental Medicine, Pittsburgh, Pennsylvania, United States

${ }^{5}$ Department of Pediatric Dentistry, UCSF School of Dentistry, San Francisco, California, United States

6 University Medical Center, University of Mainz, Mainz, Germany

${ }^{7}$ Department of Periodontology and Operative Dentistry, University Medical Center, University of Mainz, Mainz, Germany

${ }^{8}$ Department of Otolaryngology, Head and Neck Surgery, University Medical Center, University of Mainz, Mainz, Germany

${ }^{9}$ Department of Diagnostic and Biomedical Sciences, Technology Services and Informatics, University of Texas Health Science Center at Houston (UTHealth) School of Dentistry, Houston, Texas, United States

${ }^{10}$ The University of Sydney School of Dentistry, Westmead, New South Wales, Australia

Appl Clin Inform 2019;10:367-376.

\begin{abstract}
Address for correspondence Elsbeth Kalenderian, DDS, MPH, PhD, Department of Preventive and Restorative Dental Sciences, UCSF School of Dentistry, 707 Parnassus Avenue, San Francisco, CA 94143, United States (e-mail: Elsbeth.Kalenderian@ucsf.edu).
\end{abstract}
Abstract
Keywords
- electronic health records
- technology
- dental
- healthcare delivery
- integrated
- medical record
- patient safety

Objectives Electronic health records (EHRs) are rarely shared among medical and dental providers. The purpose of this study was to assess current information sharing and the value of improved electronic information sharing among physicians and dentists in Germany and the United States.

Materials and Methods A survey was validated and distributed electronically to physicians and dentists at four academic medical centers. Respondents were asked anonymously about EHR use and the medical and dental information most valuable to their practice.

Results There were 118 responses, a response rate of $23.2 \%$. The majority (63.9\%) of respondents were dentists and the remainder were physicians. Most respondents (66.3\%) rated the importance of sharing information an 8 or above on a 1-to-10 Likert scale. Dentists rated the importance of sharing clinical information significantly higher than physicians $(p=0.0033)$. Most $(68.5 \%)$ providers could recall an instance when received

February 12, 2019

accepted after revision

April 8, 2019 (c) 2019 Georg Thieme Verlag KG Stuttgart · New York
DOI https://doi.org/

$10.1055 / \mathrm{s}-0039-1688832$.

ISSN 1869-0327. 
access to medical or dental information would have improved patient care. Dentists were significantly more likely to report this than physicians $(p=0.008)$.

Conclusion Physicians would value a standardized measure of "oral health" in their EHR. Dentists were less likely to find specific medical diagnostic test results of value. Both dentists and physicians agreed that oral-systemic health was important; interoperable EHRs could facilitate information transfer between providers and enhance research on oral-systemic health connections. Both dentists and physicians believed that an interoperable EHR would be useful to practice, but desired information was different between these groups. Refinement of the information needed for shared practice is required.

\section{Background and Significance}

Since 1991, when the Institute of Medicine (IOM) released its report The Computer-Based Patient Record (CPR): An Essential Technology for Healthcare, the use of an electronic health record (EHR) has been considered a critical feature of the modern healthcare delivery system. ${ }^{1}$ While the IOM anticipated that EHRs would become the standard health record within 10 years, EHR adoption lagged until the $2009 \mathrm{HITECH}$ (Health Information Technology for Economic and Clinical Health) Act. Through its $\$ 27$ billion incentives, the HITECH Act has actively promoted adoption of EHRs that meet standards of Meaningful Use (MU) intended to improve patient care coordination, safety, and privacy. ${ }^{2}$

This historical development proceeded similar in Germany. In 1997, Berger et al described a multimedia electronic patient record with the goal of increasing quality and reach of patient care. Furthermore, this advancement in communication and cooperation should increase economic efficiency of healthcare delivery. ${ }^{3}$ On these grounds, Germany implemented a personal electronic health card in 2004 followed by an E-Health Law in 2015 that incentivized EHR adoption in the country. Despite these governmental efforts, implementation of EHRs remains an individual decision of each care facility and their utilization differs widely between individual physicians and dentists respectively.

Nearly three-quarters of physicians now utilize digital EHRs, with rates highest among primary care physicians. ${ }^{4}$ Similar rates of adoption have been found within dentistry, with greater than 70 percent of respondents in one large survey reporting chairside EHR use, although dental providers are less likely to exclusively use digital records and are less likely to take advantage of MU incentives. ${ }^{5,6}$ Smaller and more rural dental practices are less likely to adopt EHR technology. ${ }^{7}$

Key functions of both medical and dental EHRs include data integration, information exchange, and enhanced interprovider communication. ${ }^{8}$ EHRs can also be used to identify adverse events and provide more sophisticated data monitoring. ${ }^{9,10}$ Critically, interoperability between health systems and EHR products allows up-to-date electronic health information exchange and the use of patients' most current information by care providers and other recipients of the data. ${ }^{11,12}$

Seamless interoperability is vitally important to quality of care, efficiency, and patient safety in the current healthcare environment. In spite of the HITECH Act's incentives, there is evidence to suggest that providers' and systems' attempts to meet the MU incentive's data capture requirements may have resulted in decreased, rather than increased, information exchange. ${ }^{11,13}$ Most recently, the 21st Century Cures Act, passed in 2016, contains several provisions to enhance interoperability, and its impact on current health information exchange is still evolving. ${ }^{14,15}$ True interoperability, even among medical EHRs, remains rare, and is often reliant upon unrelated hospital systems purchasing the same EHR package. ${ }^{16}$ Additionally, within both medicine and dentistry, consensus is still being reached on key components of clinical care and health information that should be universally recorded within a patient's EHR. ${ }^{17}$ Another hurdle is the development of documentation standards for electronic dental records, which have not been satisfactorily nor frequently used. ${ }^{18,19}$

As a result, information exchange between medical and dental EHRs is essentially nonexistent, with only rare examples in the literature. ${ }^{20}$ While there are myriad dental and medical EHR software packages on the market, most medical EHRs do not include a dental module, or at best include a "stand alone" dental module, and most dental EHRs are not interoperable with medical EHRs.

Surveyed physicians have indicated that their medical decisions would be impacted by access to patients' oral health record; medical specialists and administrative units have also indicated that some oral health information is critical to a complete health record. ${ }^{21,22}$ Examples of information previously identified as of value to medical providers include logistics such as dental appointment times and clinical information such as prescribed medications, as well as enhanced communication (i.e., more seamless referral to providers). ${ }^{22}$ Both medical and dental providers agree that enhanced information sharing will benefit practice. ${ }^{23}$ The ideal of a single, cohesive EHR for both patient and provider benefit will only be truly met through improved interoperability of the various EHRs and clinical interfaces currently in use by different providers and health systems. 
Lack of free information sharing between medical and dental providers places the burden of information sharing onto patients, who may be unable to accurately describe their health history or fully list the medications they take. Vulnerable patients with low health literacy are at especially high risk of experiencing adverse outcomes or suboptimal care as a result of these systems-based failures. ${ }^{24}$

A large body of recent research has emphasized the connections between oral and systemic health and the role of oral health outcomes in overall health. ${ }^{25-28}$ In addition to benefits for medical providers, efficient health information systems can provide timely, accurate, and accessible patient information to dental providers. ${ }^{29}$ Assessing the extent of dental and medical providers' healthcare information needs and developing an interoperable system of electronic medical and dental information are the next steps in improving patient safety and outcomes in the medical and dental setting.

The purpose of this study was to assess what information sharing is perceived as most valuable for medical and dental providers, and to assess the extent of current electronic information sharing between these providers.

\section{Materials and Methods}

\section{Participants}

The surveyed medical and dental respondents represented three U.S. dental schools and single foreign university hospital, each with corresponding onsite medical facilities. None of the four sites had an interoperable medical-dental EHR in standard practice at the time of survey dissemination. All invited participants were fully licensed physicians or dentists who provided at least part-time clinical care at the university-affiliated facility. Participation in the survey was voluntary, responses were anonymous, and participants could only respond once (multiple responses were not permitted). Human subjects review board approval was obtained separately from each participating institution.

\section{Data Collection and Sampling}

Each study site within the United States administered the email-based survey to local/onsite respondents on behalf of the investigative laboratory through the Qualtrics survey platform (Seattle, Washington, United States). The foreign site (site 4) distributed the survey via the hospital's internal mail service. Although the survey was anonymous, the total number of recipients of the email was known and used for response rate calculations. The survey's purpose was to perform an assessment regarding the knowledge and practical use regarding the synchronization of electronic medical and dental records among healthcare providers. The survey titled "Implementing inter-operability of electronic health records for physicians and dentists" consists of 61 items. The survey was developed and subsequently validated by the authors. Data from the eligible medical and dental providers were collected between April 2016 through January 2018 and the survey duration varied by site. Due to differences in survey distribution methods, sites 1 and 4 each administered the survey for 6 weeks, while site 2 was open for 6 months, and site 3 for 1.5 years. Dentists with any clinical dental degree (e.g., DMD, DDS, BDS) as well as physicians with any clinical medical degree (MD, DO) were eligible to participate. Each survey recipient received a detailed information sheet identifying the investigators and the general intent of the research. Face validation was established with an in-person meeting with postgraduate dentists consisting of multiple specialties (endodontics, orthodontics, and prosthodontics residents) recruited from one of the sites. A convenience sample of seven dentists contributed to survey face validity testing through in-depth discussion of each survey item. Reliability was evaluated with 10 postgraduate dentists who completed the survey twice 1 week apart. The average percent agreement was $91.95 \%$, and the average kappa was $81.66 \%$. The same group participated in pilot testing of the digital survey interface. The surveys used for the foreign-site cohort (site 4) were translated by a native speaking coauthor and the result was reviewed by both medical and dental professionals to ensure correctness.

\section{Statistical Analysis}

Descriptive analyses report the frequencies and percent contributions for each survey item. To assess whether there were significant differences between medical and dental provider responses, we utilized nonparametric rank sum tests for ordinally measured survey items and chi-squared tests for categorical variables. No multivariate associations were evaluated. To control the type 1 error rate, we employed the Benjamini-Hochberg false discovery rate method. ${ }^{30}$ For the power analysis, we computed the minimum detectable effect size of 0.32 (Cohen's $d=0.32$ ) for the standard significance level ( $\alpha=0.05$ ), power ( $80 \%$ ), and the sample size of 118 providers. All statistical analyses were conducted at the 0.05 significance level and performed using Stata Statistical Software release 15 for StataCorp LP (2015, College Station, Texas, United States).

\section{Results}

The survey was disseminated to 508 physicians and dentists at the four sites and the overall response rate was $23.2 \%$. The demographic data are summarized in -Table 1, and professional characteristics of the study participants are exhibited in -Table 2. Most respondents were dentists (76; 63.9\%) and $36.1 \%$ (43) were physicians. There were a total $33(28.0 \%)$ responses from site 1,22 (18.6\%) from site 2,17 (14.4\%) from site 3 , and 46 (39.0\%) from site 4 . Among those who responded, the most frequently reported dental specialty was "prosthodontics" and the most frequently seen physician specialty was internal medicine/internist. Approximately 7 in 10 responding physicians were internists, pediatricians, or orthopaedic surgeons. The clinic hours of physicians were significantly more than the dentists, the hours spent performing student supervision were significantly higher among dentists, and there was no difference in administrative tasks among physicians and dentists. 
Table 1 Provider demographics

\begin{tabular}{|c|c|c|c|}
\hline & Dentist & Physician & $p$-Value \\
\hline Provider type & $76(63.9 \%)$ & $43(36.1 \%)$ & - \\
\hline Years in practice & $17.9(15.0)$ & $15.5(11.1)$ & 0.96 \\
\hline \multicolumn{4}{|l|}{ Roles in practice } \\
\hline Clinical & & & 0.001 \\
\hline Yes & $13(44.8 \%)$ & $16(94.1 \%)$ & \\
\hline No & $16(55.2 \%)$ & $1(5 . \%)$ & \\
\hline \multicolumn{4}{|l|}{ Student supervision } \\
\hline Yes & $20(69.0 \%)$ & $11(64.7 \%)$ & \\
\hline No & $9(31.0 \%)$ & $6(35.3 \%)$ & \\
\hline \multicolumn{4}{|c|}{ Administration (patient scheduling, follow-up, etc) } \\
\hline Yes & $20(69.0 \%)$ & $12(70.6 \%)$ & \\
\hline No & $9(31.0 \%)$ & $5(29.4 \%)$ & \\
\hline Survey performance site & & & 0.043 \\
\hline Germany & $16(21.3 \%)$ & $17(39.5 \%)$ & \\
\hline HSDM & $15(20.0 \%)$ & $7(16.3 \%)$ & \\
\hline Pitt & $15(20.0 \%)$ & $2(4.7 \%)$ & \\
\hline UCSF & $29(38.7 \%)$ & $17(39.5 \%)$ & \\
\hline \multicolumn{4}{|c|}{ How many electronic health record systems (EHRs) do you use regularly? } \\
\hline 0 & $17(32.1 \%)$ & $0(0.0 \%)$ & $<0.0001$ \\
\hline 1 & $20(37.7 \%)$ & $21(60.0 \%)$ & \\
\hline 2 & $8(15.1 \%)$ & $10(28.6 \%)$ & \\
\hline 3 & $4(7.6 \%)$ & $3(8.6 \%)$ & \\
\hline 4 & $2(3.8 \%)$ & $1(2.9 \%)$ & \\
\hline 5 & $3(3.8 \%)$ & $0(0.0 \%)$ & \\
\hline
\end{tabular}

Abbreviations: HSDM, Harvard School of Dental Medicine; UCSF, University of California, San Francisco.

At least $80.9 \%$ of our cohort used at least one EHR regularly. German respondents reported using significantly fewer EHRs, on average, than U.S. respondents (1.64 vs.0.74 EHRs, $p<0.0001)$. This was primarily because most German dentists did not report using an EHR (13/16 respondents). AxiUm (Las Vegas, Nevada, United States) (39.5\%) was most frequently used among dentist while Apex (Harlow, Essex) (29.2\%) was most frequently used among physicians.

The majority of both dentists (79.2\%) and physicians (60.6\%) agreed that it was either very or extremely useful having patients' medical/dental information available in the EHR. When asked to rate the relative importance of sharing clinical information between medical and dental providers on a scale of 1 to $10,66.3 \%$ of all respondents rated it as an 8 or above. Further, dental providers were significantly more likely to ascribe a higher rating on the importance of sharing clinical information than physicians $(p$-value $=0.0033)$. Nearly one in three of all surveyed providers reported that they rarely requested a consult for their patients from a corresponding physician/dentist. Dental providers were significantly more likely to seek daily and weekly consults from other physicians $(p$-value $=0.003)$. These consultations most often took the form of phone calls and postprocedure patient instructions. In total, $35.6 \%$ of all surveyed providers rarely received a patient referral from a corresponding physician/dentist, and dentists were significantly more likely than physicians to receive daily, weekly, and monthly referrals from other physicians. In response to determining which physician/dentist to refer their patients to, providers indicated that they most often practiced in a healthcare system or group that included physicians and dentists. Second to that, they seemed to encourage patients to see their physician/dentist of record (see - Table 3 ).

Provided it was secure and confidential, $67.0 \%$ of all surveyed providers reported that it would be very/extremely useful to their practice if their patient's medical/dental information was accessible. Medications, medical findings noted at a dental visit (elevated blood pressure, elevated blood glucose), and allergy represent the dental records information that the surveyed dentists would like a patient's physician to access in an integrated EHR. Alternatively, medications, patient diagnosis, and medical history represent the medical record information that surveyed dentists would like to access in an integrated EHR (- Fig. 1). 
Table 2 Provider specialties

\begin{tabular}{|l|l|}
\hline Provider type/specialty (DMD) & Freq. (\%) \\
\hline General dentistry & $10(13.3)$ \\
\hline Dental public health & $2(2.7)$ \\
\hline Periodontics & $10(13.3)$ \\
\hline Orthodontics & $9(12.0)$ \\
\hline Oral and maxillofacial surgery & $4(5.3)$ \\
\hline Oral medicine,oral pathology & $0(0.0)$ \\
\hline Endodontics & $3(4.0)$ \\
\hline Prosthodontics & $12(16.0)$ \\
\hline Pediatric dentistry & $2(2.7)$ \\
\hline Other & $3(4.0)$ \\
\hline Unanswered & $20(26.7)$ \\
\hline Provider type/specialty (MD) & \\
\hline Internal medicine & $13(30.2)$ \\
\hline Family medicine & $3(7.0)$ \\
\hline Cardiology & $6(14.0)$ \\
\hline Orthopaedic surgery & $7(16.3)$ \\
\hline Pediatrics & $10(23.3)$ \\
\hline Other & $3(7.0)$ \\
\hline Unanswered & $1(2.3)$ \\
\hline
\end{tabular}

Abbreviations: DMD, Doctor of Dental Medicine; MD, Doctor of Medicine.

Surveyed providers reported that constant availability, better collaboration for coordinated care, information exchanges, and time saving as advantages of an integrated EHR while data protection, patient privacy, and error transfer were mentioned as disadvantages. In total, $68.5 \%$ of all surveyed providers could recall a specific instance when access to corresponding medical/dental information could have improved dental/medical care for their patients and dentists were significantly more likely to report those instances than physicians ( $p$-value $=0.008$ ). In addition, $58.7 \%$ of all providers reported reading healthcare journals or attending conferences where the subject of the oralsystemic health connection was discussed. Dentists reported significantly higher rates of reading healthcare journals related to oral-systemic health or attendance of related conferences relative to their physician counterparts ( $p$-value $<0.0001$ ). On a scale from 1 to $10,73.3 \%$ of all providers rated the relative importance of the oral-systemic health connection to the well-being of their patients as an 8 or higher. Approximately 4 in 10 of all providers reported that patients ever mention that dental and medical information could be more integrated to ease the coordination of their overall healthcare (-Table 4).

There were some notable differences between German and U.S. respondents. As mentioned above, German dentists were less likely to be using an EHR. These respondents were more likely to report practicing in a group that included physicians ( 10 respondents, $58.8 \%$, vs. 17 respondents, $24.3 \%$, $p=0.006)$. Providers at the German site were also less likely to recall a specific instance when access to medical information could have improved dental care for one of their patients (14 respondents (42.4\%) vs.47 respondents (78.3\%), $p<0.0001)$.

\section{Discussion}

Our multisite study of medical and dental providers at academic centers found that $77 \%$ of dentist respondents and $57 \%$ of physician respondents believed that the connection between oral and systemic health impacted their patients and that access to medical and dental information through their EHR would improve care. The core aspects of a patient's dental treatment and dental history rated to be most useful to medical providers by respondents in our study align with other medical provider priorities previously described in the literature. ${ }^{21,22}$

While both dentists and physicians believed that shared information within an EHR would be highly useful to their practice, the exact nature of the desired shared information was different between these two types of clinicians. There were significant differences between the rates of specific medical information that the dentists wished to access to and what the physicians would like the dentists to access, with dentists less likely to desire access to electrocardiograms, cardiac stress tests, medical imaging, and immunizations. This discrepancy may be due to a difference in knowledge levels for interpretation of these more sophisticated results, or an uncertainty in how these results may inform dental treatment. The majority of dentist respondents also indicated that sharing of patients' vital signs and social history would not be useful. As responses were binary, it is unknown whether this is because dentists routinely collect this information themselves, or because they believe it would not inform their practice. Given the known associations between aspects of the social history including socioeconomic status, $^{31}$ substance use, ${ }^{32}$ immigration status, ${ }^{33}$ and dental disease, an interoperable EHR including shared social history may assist with overcoming patients' known barriers to treatment.

Interestingly, while only the minority of physicians wished to have access to patients' dental problem lists (e.g., list of dental diagnoses), tooth chart, and dental history, a much higher percentage indicated that the shared metric of "oral health status" would be of value to their practice. This suggests that physicians desire a more scoping summative metric of patients' oral health, rather than the more detailed dental health information listed in the problem list or odontogram. While metrics of risk assessment, such as Caries Management by Risk Assessment (CAMBRA), ${ }^{34}$ and subjective measures such as the Oral Health-Related Quality of Life $^{35}$ have been validated, their applicability to medical providers has not been studied; these tools only encapsulate one aspect of oral health, rather than providing a succinct picture of oral health status that may be of value to medical providers. Recent attempts to derive a standard set of oral health outcomes, such as by the International Consortium for 
372 Improving Oral-Systemic Health Care through Medical and Dental EHRs Simon et al.

Table 3 Electronic health record (EHR) and electronic medical record (EMR) requests

\begin{tabular}{|c|c|c|c|}
\hline & Dentist & Physician & $p$-Value \\
\hline \multicolumn{4}{|c|}{$\begin{array}{l}\text { At times, would having your patient's medical/ } \\
\text { dental information available at your fingertips in } \\
\text { your EHR improve the provision/coordination of } \\
\text { effective care? }\end{array}$} \\
\hline Extremely useful & $28(52.8 \%)$ & $9(27.3 \%)$ & 0.019 \\
\hline Very useful & $14(26.4 \%)$ & $11(33.3 \%)$ & \\
\hline Useful & $9(17.0 \%)$ & 7 (21.2\%) & \\
\hline Not very useful & $1(1.9 \%)$ & $6(18.2 \%)$ & \\
\hline Not at all useful & $1(1.9 \%)$ & $0(0.0 \%)$ & \\
\hline \multicolumn{4}{|c|}{$\begin{array}{l}\text { On a scale of } 1 \text { to } 10 \text {, please rate the relative } \\
\text { importance of sharing clinical information about } \\
\text { your patients with their medical/dental providers }\end{array}$} \\
\hline 1 & $0(0.0 \%)$ & $0(0.0 \%)$ & 0.0033 \\
\hline 2 & $1(1.9 \%)$ & $3(7.3 \%)$ & \\
\hline 3 & 1 (1.9\%) & $5(12.2 \%)$ & \\
\hline 4 & $1(1.9 \%)$ & $2(4.9 \%)$ & \\
\hline 5 & $5(9.3 \%)$ & $3(7.3 \%)$ & \\
\hline 6 & $0(0.0 \%)$ & $2(4.9 \%)$ & \\
\hline 7 & $4(7.4 \%)$ & $5(12.2 \%)$ & \\
\hline 8 & $11(20.4 \%)$ & $9(22.0 \%)$ & \\
\hline 9 & 7 (13.0\%) & $2(4.9 \%)$ & \\
\hline \multirow[t]{2}{*}{10} & $24(44.4 \%)$ & $10(24.4 \%)$ & \\
\hline & 5.4 & 4.1 & \\
\hline \multicolumn{4}{|c|}{$\begin{array}{l}\text { How frequently do you request a consult for one of } \\
\text { your patients from a physician/dentist? }\end{array}$} \\
\hline Daily & $6(11.1 \%)$ & $0(0.0 \%)$ & 0.003 \\
\hline Weekly & $19(35.2 \%)$ & $6(14.6 \%)$ & \\
\hline Monthly & 17 (31.5\%) & $13(31.7 \%)$ & \\
\hline Rarely & $11(20.4 \%)$ & $20(48.8 \%)$ & \\
\hline Never & $1(1.9 \%)$ & $2(4.9 \%)$ & \\
\hline \multicolumn{4}{|c|}{$\begin{array}{l}\text { How frequently do you receive a patient referral } \\
\text { from a physician/dentist? }\end{array}$} \\
\hline Daily & $10(27.0 \%)$ & $0(0.0 \%)$ & $<0.0001$ \\
\hline Weekly & $10(27.0 \%)$ & $1(2.4 \%)$ & \\
\hline Monthly & $14(37.8 \%)$ & $5(12.2 \%)$ & \\
\hline Rarely & $1(2.7 \%)$ & 27 (65.9\%) & \\
\hline Never & $2(5.4 \%)$ & $8(19.5 \%)$ & \\
\hline \multicolumn{4}{|c|}{$\begin{array}{l}\text { How do you determine which physician/dentist to } \\
\text { refer to? }\end{array}$} \\
\hline \multicolumn{4}{|c|}{$\begin{array}{l}\text { I have a documented relationship with certain } \\
\text { physicians (dentist) }\end{array}$} \\
\hline Yes & $9(20.5 \%)$ & $4(9.3 \%)$ & 0.229 \\
\hline No & 35 (79.5\%) & $39(90.7 \%)$ & \\
\hline \multicolumn{4}{|c|}{$\begin{array}{l}\text { I practice in a healthcare system or group that } \\
\text { includes physicians (dentist) }\end{array}$} \\
\hline Yes & $6(13.6 \%)$ & $21(48.8 \%)$ & $<0.0001$ \\
\hline No & $38(86.4 \%)$ & 22 (51.2\%) & \\
\hline
\end{tabular}


Table 3 (Continued)

\begin{tabular}{|l|l|l|l|}
\hline & Dentist & Physician & $p$-Value \\
\hline I use the internet to search for physicians (dentist) & & & \\
\hline Yes & $1(2.3 \%)$ & $2(4.7 \%)$ & 0.616 \\
\hline No & $43(97.7 \%)$ & $41(95.3 \%)$ & \\
\hline $\begin{array}{l}\text { I encourage the patient to see their physician } \\
\text { (dentist) of record }\end{array}$ & & & \\
\hline Yes & $17(38.6 \%)$ & $19(44.2 \%)$ & 0.666 \\
\hline No & $27(61.4 \%)$ & $24(55.8 \%)$ & \\
\hline Other & & & \\
\hline Yes & $2(4.6 \%)$ & $4(9.3 \%)$ & 0.434 \\
\hline No & $42(95.4 \%)$ & $39(90.7 \%)$ & \\
\hline
\end{tabular}

Health Outcomes Measurement, present another potential model of summarized information sharing. ${ }^{36}$ Future efforts should focus on better understanding the aspects of oral health status that would be most valuable to medical providers and refinement of a model to present this information to clinicians.

Both medical and dental respondents in this study were asked to determine the impact of interoperable EHRs on their practice, but it is important to note that increased data sharing among providers may also have potential benefits to patients that extend beyond the relatively siloed care provided by individual clinicians. For example, evaluation of diabetes risk is more sensitive when both medical and dental variables are incorporated into the risk algorithm. ${ }^{37}$ Access to additional unstructured clinical data from encounter notes may also increase the sensitivity of natural language processing to other important health conditions, such as tobacco use. ${ }^{38,39}$ Chairside screening interventions for chronic diseases including substance use disorders, ${ }^{40}$ eating disorders, ${ }^{41}$ cardiovascular disease, ${ }^{42}$ diabetes, ${ }^{43}$ and obesity $^{44}$ have all been validated, but appropriate referral of patients found to be at high risk has been described as a hurdle. ${ }^{45}$ While not explored as part of this study, automated sharing of these results with patients' medical teams would allow for ideal patient management and prompt referral to necessary providers. Similarly, interoperable records would maximize evaluation of oral health risk factors in the medical setting by seamlessly sharing findings with dental providers, and possibly helping to reduce inappropriate medical resource use for dental problems, for example by notifying a dentist that a patient presented to the emergency department with tooth pain. ${ }^{46}$ Lastly, there is enhanced potential for research to better understand health risks and improve outcomes if EHRs include both medical and dental data. ${ }^{10}$

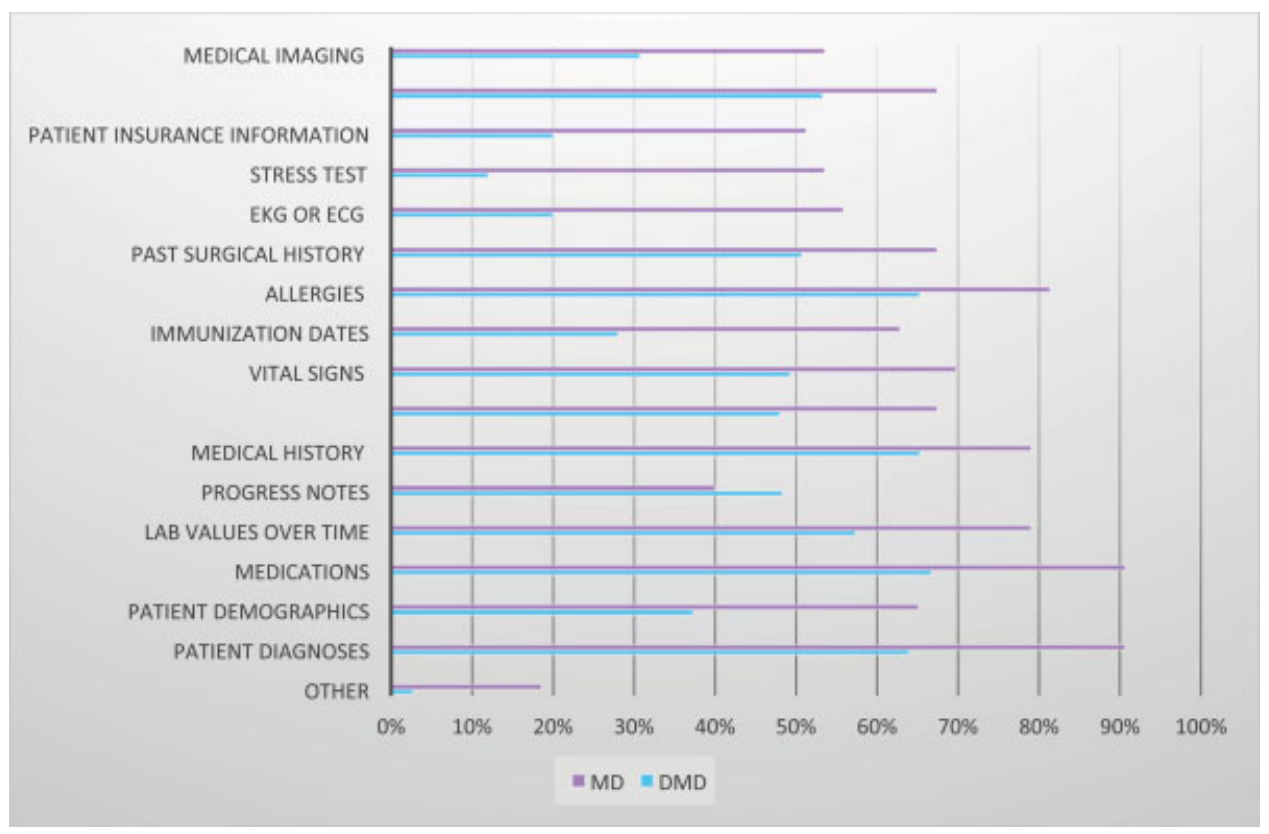

Fig. 1 Medical information that the physician (MD) would want the patient's dentist (DMD) to access versus medical information that the dentist would like to access in an integrated EHR. DMD, Doctor of Dental Medicine; EHR, electronic health record; MD, Doctor of Medicine. 
Table 4 Electronic health record and electronic medical record knowledge

\begin{tabular}{|c|c|c|c|}
\hline & Dentist & Physician & $p$-Value \\
\hline \multicolumn{4}{|c|}{$\begin{array}{l}\text { Can you recall a specific instance when access to } \\
\text { medical/dental information could have improved } \\
\text { dental/medical care for one of your patients? }\end{array}$} \\
\hline Yes & 40 (76.9\%) & 21 (56.8\%) & 0.008 \\
\hline No & 12 (23.1\%) & $16(43.2 \%)$ & \\
\hline \multicolumn{4}{|c|}{$\begin{array}{l}\text { Do you read any health care journals or attend any } \\
\text { conferences where the subject of the oral-systemic } \\
\text { health connection has been discussed? }\end{array}$} \\
\hline Yes & 40 (78.4\%) & 14 (34.2\%) & $<0.0001$ \\
\hline No & $11(21.6 \%)$ & 27 (65.8\%) & \\
\hline \multicolumn{4}{|c|}{$\begin{array}{l}\text { On a scale from } 1 \text { to } 10 \text {, please rate the relative } \\
\text { importance of the oral-systemic health connection } \\
\text { to the well-being of your patients. }\end{array}$} \\
\hline 1 & $0(0.0 \%)$ & $0(0.0 \%)$ & 0.0001 \\
\hline 2 & $0(0.0 \%)$ & $1(2.6 \%)$ & \\
\hline 3 & 1 (1.9\%) & $1(2.6 \%)$ & \\
\hline 4 & 1 (1.9\%) & 2 (5.1\%) & \\
\hline 5 & 2 (3.9\%) & $6(15.4 \%)$ & \\
\hline 6 & $2(3.9 \%)$ & $2(5.1 \%)$ & \\
\hline 7 & $0(0.0 \%)$ & $6(15.4 \%)$ & \\
\hline 8 & 12 (23.1\%) & $11(28.2 \%)$ & \\
\hline 9 & $11(21.2 \%)$ & $2(5.1 \%)$ & \\
\hline 10 & 23 (44.2\%) & 7 (18.0\%) & \\
\hline \multicolumn{4}{|c|}{$\begin{array}{l}\text { Do your patients ever mention that dental and } \\
\text { medical information could be more integrated to } \\
\text { ease the coordination of their overall healthcare? }\end{array}$} \\
\hline Yes & 28 (53.9\%) & 11 (27.5\%) & 0.019 \\
\hline No & $24(46.1 \%)$ & 29 (72.5\%) & \\
\hline
\end{tabular}

Among medical providers, the most commonly used EHR was Epic (Epic Systems, Verona, Wisconsin, United States), which does offer the wisdom dental module. ${ }^{47}$ However, no dental respondents indicated utilization of this EHR. While the majority of physicians utilized only one EHR regularly, it is important to note that a plurality of dentists reported not using any EHR with regularity, which could limit the applicability of our survey findings; however, the rate of EHR utilization among dentist respondents in our study is actually higher than that of dentists in private practice in the United States. ${ }^{48}$

In the German cohort, medical providers used mostly Orbis (Agfa HealthCare GmbH, Bonn, Germany). No dental participants declared to be using this program. Utilization of EHRs within the German dental group was lower, and only three respondents reported using an EHR. In this group, LinuDent (Pharmatechnik GmbH \& Co. KG, Starnberg, Germany) was the most frequently used EHR.

There exist differences in education as well as in clinical health care between the United States and Germany, primarily related to the structural build-up of academic programs, their funding, general health care expenditure, and the insurance system. ${ }^{49,50}$ In our cohort, more dentists in Germany reported sharing a practice with physician colleagues. However, in both countries medicine and dentistry remain separate academic programs with separate clinical faculties with a similar scope in both countries. While it would seem that German dentists have further to progress toward EHR adoption, the general issues of interprofessional communication occur in both settings.

This study had several limitations. This was an exploratory study intended to identify what information would be most useful for respondents. We are unable to conclude whether this sample is representative of any particular population of physicians or dentists. Clinicians who are more aware of or affected by the separation of medical and dental records may have been more likely to respond to the survey invitation. The survey had a low response rate of $23.2 \%$, with a substantially higher response rate among dentists than physicians, and a higher number of dentist respondents overall. Dentists were also more likely to inhabit nonclinical roles, which limits the applicability of these responses to the average practicing clinician. Future studies should be tailored to the needs of clinicians in various 
practice settings, such as community health centers, private practices, or hospitals, as well as specific dental and medical specialties whose health information needs may vary considerably.

\section{Clinical Relevance Statement}

This manuscript describes the information needs of both medical and dental providers. The results can inform future interoperable record design to maximize usefulness for both medical and dental providers, as both groups of providers reported separate priorities when sharing health information. The results may also help dental and medical providers communicate important patient information to each other.

\section{Multiple Choice Questions}

1. Which electronic health record was most commonly used among medical provider respondents?
a. AxiUm.
b. Epic.
c. Apex.
d. Dentrix.

Correct Answer: The correct answer is option c.

2. A significant difference between physician and dental respondents was:

a. A significantly higher number of dentists worked outside the United States.

b. Physician respondents were significantly more likely to work in a healthcare system with dentists.

c. Dentists were significantly more likely to encourage patients to visit their physician of record.

d. Physicians were significantly more likely to use the internet to search for dental providers.

Correct Answer: The correct answer is option b.

\section{Protection of Human and Animal Subjects}

Human subjects review board approval was obtained from all sites at which the survey was administered (Harvard University, University of California San Francisco, University of Pittsburgh, and Bonn University).

\section{Conflict of Interest}

None declared.

\section{Acknowledgments}

Our most sincere gratitude to Dr. Brad Rindal for his contributions to the manuscript.

\section{References}

1 Berner ES, Detmer DE, Simborg D. Will the wave finally break? A brief view of the adoption of electronic medical records in the United States. J Am Med Inform Assoc 2005;12(01):3-7

2 Butler B, Murphy J. The impact of policies promoting health information technology on health care delivery in jails and local communities. Health Aff (Millwood) 2014;33(03):487-492
3 Berger R, Partner Gmb H. Telematik Im Gesundheitswesen-Perspektiven Der Telemedizin in Deutschland-Für. Roland Berger \& Partner GmbH: Munich; 1997

4 Jamoom EW, Yang N, Hing E. Adoption of certified electronic health record systems and electronic information sharing in physician offices: United States, 2013 and 2014. NCHS Data Brief 2016;236:1-8

5 Acharya A, Schroeder D, Schwei K, Chyou P-H. Update on electronic dental record and clinical computing adoption among dental practices in the United States. Clin Med Res 2017;15(34):59-74

6 Kalenderian E, Walji M, Ramoni RB. "Meaningful use" of EHR in dental school clinics: how to benefit from the U.S. HITECH Act's financial and quality improvement incentives. J Dent Educ 2013; 77(04):401-415

7 Chauhan Z, Samarah M, Unertl KM, Jones MW. Adoption of electronic dental records: examining the influence of practice characteristics on adoption in one state. Appl Clin Inform 2018;9 (03):635-645

8 Simborg DW, Detmer DE, Berner ES. The wave has finally broken: now what? J Am Med Inform Assoc 2013;20(e1):e21-e25

9 Kalenderian E, Walji MF, Tavares A, Ramoni RB. An adverse event trigger tool in dentistry: a new methodology for measuring harm in the dental office. J Am Dent Assoc 2013;144(07):808-814

10 Walji MF, Kalenderian E, Stark PC, et al. BigMouth: a multiinstitutional dental data repository. J Am Med Inform Assoc 2014;21(06):1136-1140

11 Studeny J, Coustasse A. Personal health records: is rapid adoption hindering interoperability? Perspect Health Inf Manag 2014;11:1e

12 Kalenderian E, Halamka JD, Spallek H. An EHR with teeth. Appl Clin Inform 2016;7(02):425-429

13 Mennemeyer ST, Menachemi N, Rahurkar S, Ford EW. Impact of the HITECH Act on physicians' adoption of electronic health records. J Am Med Inform Assoc 2016;23(02):375-379

14 Lye CT, Forman HP, Daniel JG, Krumholz HM. The 21st Century Cures Act and electronic health records one year later: will patients see the benefits? J Am Med Inform Assoc 2018;25(09):1218-1220

15 Rucker D. Achieving the interoperability promise of 21st century cures. June 19, $2018 . \quad$ Available at: https://www.healthit.gov/ buzz-blog/interoperability/achieving-the-interoperability-promise-of-21st-century-cures. Accessed April 23, 2019

16 Castillo AF, Sirbu M, Davis AL. Vendor of choice and the effectiveness of policies to promote health information exchange. BMC Health Serv Res 2018;18(01):405

17 Tokede O, Ramoni RB, Patton M, Da Silva JD, Kalenderian E. Clinical documentation of dental care in an era of electronic health record use. J Evid Based Dent Pract 2016;16(03):154-160

18 White JM, Kalenderian E, Stark PC, Ramoni RL, Vaderhobli R, Walji MF. Evaluating a dental diagnostic terminology in an electronic health record. J Dent Educ 2011;75(05):605-615

19 Tokede O, White J, Stark PC, et al. Assessing use of a standardized dental diagnostic terminology in an electronic health record. J Dent Educ 2013;77(01):24-36

20 Acharya A. Marshfield Clinic Health System: integrated care case study. J Calif Dent Assoc 2016;44(03):177-181

21 Acharya A, Mahnke A, Chyou P-H, Rottscheit C, Starren JB. Medical providers' dental information needs: a baseline survey. Stud Health Technol Inform 2011;169:387-391

22 Acharya A, Shimpi N, Mahnke A, Mathias R, Ye Z. Medical care providers' perspectives on dental information needs in electronic health records. J Am Dent Assoc 2017;148(05):328-337

23 Glurich I, Schwei KM, Lindberg S, Shimpi N, Acharya A. Integrating medical-dental care for diabetic patients: qualitative assessment of provider perspectives. Health Promot Pract 2018;19(04):531-541

24 Romero-Sanchez J, Garcia-Cardenas V, Abaurre R, Martínez-Martínez F, Garcia-Delgado P. Prevalence and predictors of inadequate patient medication knowledge. J Eval Clin Pract 2016;22(05): 808-815 
25 Glick M. Exploring our role as health care providers: the oralmedical connection. J Am Dent Assoc 2005;136(06):716, 718, 720

26 Donoff B, McDonough JE, Riedy CA. Integrating oral and general health care. N Engl J Med 2014;371(24):2247-2249

27 Simon L. Overcoming historical separation between oral and general health care: interprofessional collaboration for promoting health equity. AMA J Ethics 2016;18(09):941-949

28 Elani HW, Simon L, Ticku S, Bain PA, Barrow J, Riedy CA. Does providing dental services reduce overall health care costs?: A systematic review of the literature J Am Dent Assoc 2018;149 (08):696.e2-703.e2

29 Song M, Spallek H, Polk D, Schleyer T, Wali T. How information systems should support the information needs of general dentists in clinical settings: suggestions from a qualitative study. BMC Med Inform Decis Mak 2010;10(01):7

30 Benjamini Y, Hochberg Y. Controlling the false discovery rate: a practical and powerful approach to multiple testing. J R Stat Soc 1995;57(01):289-300

31 Cohen LA, Bonito AJ, Eicheldinger C, et al. Behavioral and socioeconomic correlates of dental problem experience and patterns of health care-seeking. J Am Dent Assoc 2011;142(02):137-149

32 Baghaie H, Kisely S, Forbes M, Sawyer E, Siskind DJ. A systematic review and meta-analysis of the association between poor oral health and substance abuse. Addiction 2017;112(05):765-779

33 Wilson FA, Wang Y, Stimpson JP, McFarland KK, Singh KP. Use of dental services by immigration status in the United States. J Am Dent Assoc 2016;147(03):162.e4-169.e4

34 Cagetti MG, Bontà G, Cocco F, Lingstrom P, Strohmenger L, Campus G. Are standardized caries risk assessment models effective in assessing actual caries status and future caries increment? A systematic review. BMC Oral Health 2018;18(01):123

35 Sischo L, Broder HL. Oral health-related quality of life: what, why, how, and future implications. J Dent Res 2011;90(11): $1264-1270$

36 | ICHOM - International Consortium for Health Outcomes Measurement. Oral health. Available at: http://www.ichom.org/medical-conditions/oral-health/. Accessed September 7, 2018

37 Acharya A, Cheng B, Koralkar R, et al. Screening for diabetes risk using integrated dental and medical electronic health record data. JDR Clin Trans Res 2018;3(02):188-194
38 Patel J, Siddiqui Z, Krishnan A, Thyvalikakath T. Identifying patients' smoking status from electronic dental records data. Stud Health Technol Inform 2017;245:1281

39 Hegde H, Shimpi N, Glurich I, Acharya A. Tobacco use status from clinical notes using natural language processing and rule based algorithm. Technol Health Care 2018;26(03):445-456

40 Neff JA, Walters ST, Braitman AL, et al. A brief motivational intervention for heavy alcohol use in dental practice settings: rationale and development. J Health Psychol 2013;18(04):542-553

41 Hague AL. Eating disorders: screening in the dental office. J Am Dent Assoc 2010;141(06):675-678

42 Nasseh K, Greenberg B, Vujicic M, Glick M. The effect of chairside chronic disease screenings by oral health professionals on health care costs. Am J Public Health 2014;104(04):744-750

43 Wright D, Muirhead V, Weston-Price S, Fortune F. Type 2 diabetes risk screening in dental practice settings: a pilot study. Br Dent J 2014;216(07):E15

44 Villarosa AR, George D, Ramjan LM, Srinivas R, George A. The role of dental practitioners in addressing overweight and obesity among children: a scoping review of current interventions and strategies. Obes Res Clin Pract 2018;12(05):405-415

45 Macey R, Glenny A, Walsh T, et al. The efficacy of screening for common dental diseases by hygiene-therapists: a diagnostic test accuracy study. J Dent Res 2015;94(3, Suppl):70S-78S

46 Sun BC, Chi DL, Schwarz E, et al. Emergency department visits for nontraumatic dental problems: a mixed-methods study. Am J Public Health 2015;105(05):947-955

47 Software Epic. Available at: https://www.epic.com/software\#SpecialtiesAncillaries. Accessed September 7, 2018

48 Schleyer T, Song M, Gilbert GH, et al. Electronic dental record use and clinical information management patterns among practitioner-investigators in The Dental Practice-Based Research Network. J Am Dent Assoc 2013;144(01):49-58

49 Zavlin D, Jubbal KT, Noé JG, Gansbacher B. A comparison of medical education in Germany and the United States: from applying to medical school to the beginnings of residency. Ger Med Sci 2017;15:Doc15

50 Ridic G, Gleason S, Ridic O. Comparisons of health care systems in the United States, Germany and Canada. Mater Sociomed 2012;24 (02):112-120 